\title{
Sociology, Evaluation and Dialogue
}

\author{
Lawrence T. Nichols ${ }^{1}$
}

Published online: 14 November 2015

(C) Springer Science+Business Media New York 2015

This thematic issue on sociology and evaluation research has been many months in the making. Special thanks are due to my wife, Dr. Allison Nichols, who drew upon her own professional networks in the field of evaluation to enlist a group of distinguished participants, and who served throughout the process as the contact person between myself and the authors. I would also like to express my appreciation to the individual contributors for all the thought and effort that went into their papers, for their willingness to share on a personal level, and for their openness to the editorial guidance I provided, which in some cases meant doing multiple drafts and revisions.

Readers will find here a very rich set of papers that provide insight into teaching and service as well as applied research. Some of the data presented also has important implications for the development of academic curriculum and programs, especially at the graduate level. Along the way, readers will hear stories of how colleagues have made careers that draw upon their training in the field of sociology. In some cases, there was a relatively clear and conscious link, while other career paths were more serendipitous and the realization only gradually emerged that a sociological background was facilitating everyday duties on the job.

Throughout my term as editor I have welcomed papers about the diverse contexts of sociological work, based on the realization that most jobs and careers for those with sociological training will not be in the academic world. Thus, I am pleased that the present issue features accounts of activity in the public, non-profit and private sectors of the economy, including self-run businesses, as well as in the more limited academic sector. In the same way, the issue is enriched by the international experiences of evaluators, especially in Pakistan and Colombia.

During the past decade-partly in response to Michael Burawoy's influential 2004 presidential address to the American Sociological Association- there has been much discussion of the extent to which sociologists are, or should be, engaged with groups outside academia. Evaluation researchers are inherently engaged. Some of their work falls within Burawoy's category of "public sociology" (which he has especially

Lawrence T. Nichols

larry.nichols@mail.wvu.edu

1 Department of Sociology and Anthropology, West Virginia University, Morgantown, WV, USA 
championed) while much other work can be considered "policy sociology," a type of engagement that deserves more scholarly attention. There is a tendency to regard policy as a public matter, especially as embodied in laws at the federal (e.g., the Affordable Care Act) or the state level (e.g., regulation of fracking). But policy is also of fundamental importance at the organizational level, and organizational policies (e.g., the training of police recruits) are always in need of ongoing evaluation.

The papers presented here also speak to another issue in which I have long been interested, namely, dialogical relationships. As our authors point out, good evaluation research involves genuine dialogue with all interested parties, rather than the impersonal monologue of a distant, detached observer. Indeed, without dialogue the true facts of a situation cannot even be established in a scientific sense, because doing so requires knowledge of the point of view of participants. Thus, evaluation researchers can be promoters of expanded dialogue and an integrated stakeholder model of organizations and societies more generally, and thereby practice a more fully personalized sociology. 